\title{
The Influential Factors and Characteristics of Tight Sandstone Gas Reservoir: A Case Study in Ordos Basin in China
}

\author{
Dazhong Ren $\mathbb{D}^{1,}{ }^{1,2,3,4}$ Fu Yang, ${ }^{2}$ Rongxi $\mathrm{Li}^{3}{ }^{3}$ Yuhong Li, ${ }^{1}$ and Dengke Liu $\mathbb{D}^{2,5}$ \\ ${ }^{1}$ Xi'an Geological Survey Center, China Geological Survey, Xi'an 710054, China \\ ${ }^{2}$ Key Laboratory of Coal Resources Exploration and Comprehensive Utilization Ministry of Land and Resources, Xi'an, \\ Shaanxi 710021, China \\ ${ }^{3}$ School of Earth Science and Resources, Chang'an University, Xi'an 710054, China \\ ${ }^{4}$ Shaanxi Key Laboratory of Advanced Stimulation Technolgy for OilઐGas Reservoirs, College of Petroleum Engineering, \\ Xi'an Shiyou University, Xi'an 710021, China \\ ${ }^{5}$ School of Human Settlements and Civil Engineering, Xi'an Jiaotong University, Xi'an 710054, China
}

Correspondence should be addressed to Dazhong Ren; petro_gas@163.com

Received 2 December 2020; Accepted 10 December 2020; Published 29 December 2020

Academic Editor: Qian Yin

Copyright (C) 2020 Dazhong Ren et al. This is an open access article distributed under the Creative Commons Attribution License, which permits unrestricted use, distribution, and reproduction in any medium, provided the original work is properly cited.

\begin{abstract}
To analyze the impact of the factors on physical properties and the mechanism of tightness as well as favorable accumulation space of tight sandstone reservoir, comprehensive analysis is conducted using various kinds of experiments. The results show that the predominant rock type is medium-coarse grained lithic quartzarenite, and the main accumulating space is the dissolved secondary pores. Reservoir pore-throat structures can be divided into four categories. Based on morphologies and parameters which derived from capillary pressure curves, the physical properties rank in the following descending sequence: Type I $>$ Type II > Type III > Type IV. The reservoir quality is influenced by both sedimentation and diagenesis synthetically. The underwater distributary channel is the dominant space for favorable reservoir. Compaction and cementation play dominant roles in the reduction of permeability. The loss of primary pores caused by both those diagenesis are $20.52 \%$ and $16.91 \%$, respectively. Secondary pores formed by dissolution improve the reservoir quality by increase the porosity (2.68\%). This suggests that weak diagenesis greatly contributes to the improvement of reservoir quality.
\end{abstract}

\section{Introduction}

Tight sandstone is a heterogeneous porous media with tiny pore body and narrow pore throat [1-6]. The physical properties, sedimentary characteristics, and pore structures of tight sandstone influence their storage, migration, and transport properties. Therefore, understanding the basic information and microscopic features of the tight sandstone is the basis of figuring out the percolation mechanisms, development capabilities, and hydrocarbon occurrence states of the reservoirs [7-10]. Although lots of literature focus on those properties, the study on tight sandstone still is not enough when compared to conventional reservoirs [11-14]. Therefore, it is of great significance to study the influential factors and characteristics of the tight sandstone reservoirs.
The physical properties of tight sandstone are very complicated due to the heterogenously distributed grains and pore network, and the mechanism of tightness is dependent on those properties $[15,16]$. Numerous studies on those properties and abundant methods have been applied, and the results show that large pores dominate the pore storage while tiny pores control the percolation ability [17-19]. When it comes to favorable accumulation space of tight sandstone reservoir, currently, various techniques including observations and quantitative determination are adopted $[20,21]$. Apart from direct observation and indirect testing methods, some calculation algorithms, such as fractal theory, are applied to describe the microscopic features of tight sandstone $[3,22]$. Hence, the study on the pore structures, sedimentary features, and morphological characteristics of tight sandstone plays a key role in governing the favorable 
accumulation spaces. Thus, we picked a typical area in the Ordos basin to achieve our goals.

This paper aims to study the microscopic characteristics of tight sandstone of Shan-2 Member. We analyzed the influential factors of physical properties, the mechanism of tightness, and favorable accumulation space of tight sandstone reservoir by various kinds of tests, such as casting thin slices (CTS), scanning electron microscope (SEM), cathodoluminescence (CL), X-ray diffraction (XRD), high-pressure mercury intrusion (HPMI), physical property testing, core testing, and well logging.

\section{Methodology}

2.1. Geological Setting. Yanchang Oil and Gas Field, mainly located in Yanan City, Shaanxi Province (China), i.e., in the southeastern part of Shaanbei Slope of Ordos Basin (Figures 1(a) and 1(b)), covers $1.7 \times 10^{4} \mathrm{~km}^{2}$ and has small basement undulations. The depositional caprock has a gentle slope with no obvious anticlines, where nose-like structure develops [23-25]. With the successful gas testing in many wells in Nanniwan, Ganyegu, Qili, and Wangjiachuan in recent years, natural gas exploration shows good prospects in the Yanchang Oilfield which has took a position as the large-scale gas field. Sedimentary facies of the Shan-2 Member, the main gas production layer in the research area, is mainly braided river delta front underwater distributary channel sand body (Figure 1(c)) [26, 27]. It has poor physical properties and is a typical low porosity and low permeability tight sandstone reservoir, where the gas accumulation zone is mainly controlled by sedimentation and diagenesis [27].

2.2. Observation Methods. The CTS and SEM methods were applied for direct observation. Before CTS observation, the samples were milled to produce flat surfaces, and the rock slices were stuck in the middle. Prior to the SEM, all samples were mechanically ground, polished, and coated with carbon. ZEISS MERLIN 6174 apparatus were used for observation.

2.3. XRD. A BRUKER D8 ADVANCE X-ray diffractometer was employed for XRD measurements. The samples were crushed to the size of 80 mesh and tested at $40 \mathrm{kV}$ voltage and $30 \mathrm{~mA}$.

2.4. HPMI. The capillary pressure curves were determined using the mercury intrusion method on a Micromeritics Autopore IV 9400 apparatus. Prior to the tests, the samples were dried in an oven, evacuated at vacuum, and tested at the pressure of 1 200 MPa, the interfacial tension of mercury/air of $0.485 \mathrm{~N} / \mathrm{m}$, and the wetting angle of $\mathrm{Hg}$ of $140^{\circ}$. The calculation methods were derived from the Washburn equation and the results from Purcell $[28,29]$.

\section{Result and Discussion}

3.1. Petrographic Characteristics. According to core observation and the quantitative statistics of 107 sandstone slices, Shan-2 Member is mainly lithic quartzarenite and quartzarenite with medium-coarse grains (Figure 2). The average volume fraction of terrigenous clastic is $86.2 \%$, including $75.32 \%$ quartz, $1.94 \%$ feldspar, and $18.81 \%$ debris. The debris contains $17.62 \%$ metamorphic, $4.37 \%$ volcanic debris, and $1.28 \%$ mica.

Detrital particles have good sorting performance and low roundness and mainly contain subrounded and subangular. The particles are mainly in long contact. Cementation is mainly porous and increased porous cementation, showing that sandstone has high compositional maturity and low textural maturity in the Shan-2 Member.

The interstitial material in the Shan-2 Member has average volumetric coefficient of $14.07 \%$ and mainly consists of siliceous, kaolinite, illite, and I/S mixed layer and carbonate with the average volume coefficient of $5.81 \%, 2.9 \%, 1.72 \%$, and $2.6 \%$, respectively.

3.2. Physical Properties of the Reservoir. The analysis results of 159 samples from 47 wells in the research area show that the samples have the porosity between $5.0 \% \sim 12.0 \%$ and $7.22 \%$ on average and permeability mainly between $0.1 \sim$ $250 \times 10^{-3} \mu \mathrm{m}^{2}$ and $15.69 \times 10^{-3} \mu \mathrm{m}^{2}$ on average. The porosity is obviously positive related to the permeability (Figure 3 ), suggesting that the permeability is mainly controlled by void spaces, while the physical properties and gas content are controlled by the development of pores [30-32].

3.3. Pore Development Characteristics of the Reservoir. The observations of 107 sandstone CTS under a microscope and the results from SEM and CL show that the sandstone in the Shan-2 Member provides the surface porosity of 5.57\% and has about $38.82 \%$ residual primary intergranular pores, about $28.17 \%$ intergranular solution pores, about $24.25 \%$ intragranular solution pores, $8.26 \%$ intercrystalline pores, about $0.5 \%$ microfractures, etc. (Figure 4 ).

3.3.1. Primary Intergranular Pores. Three types of primary intergranular pores develop in this area: (1) primary intergranular pores remained after the particles are covered by chlorite lining, (2) primary intergranular pores remained after the quartz secondary overgrowth or microcrystalline calcite cement formation in the early diagenetic stage, and (3) primary pores remained after the pseudomatrix is filled in the pores formed by the deformation of plastic particles such as biotite, phyllite, and siltstone fragments. Theses pores have too small diameters to be identified under ordinary microscopes. Primary intergranular pores of the sandstone in the target zone are mainly fracture interstitial pores filled by quartz secondary overgrowth (Figure 4(a)).

3.3.2. Secondary Pores. Secondary pore is the dominant type developing in the upper Paleozoic sandstone reservoir in the research area. The pores are transformed by late diagenesis, such as pores formed due to dissolution, metasomatism, and cementation. Dissolved components are detrital particles, matrix, cements, and authigenic metasomatic minerals, including intergranular dissolution pores and intragranular dissolution pores (Figure 4(b)):

(1) Intergranular dissolution pores: there are developed by the dissolution of interstitial particles. They have obvious corrosion traces at the edge of grains and 


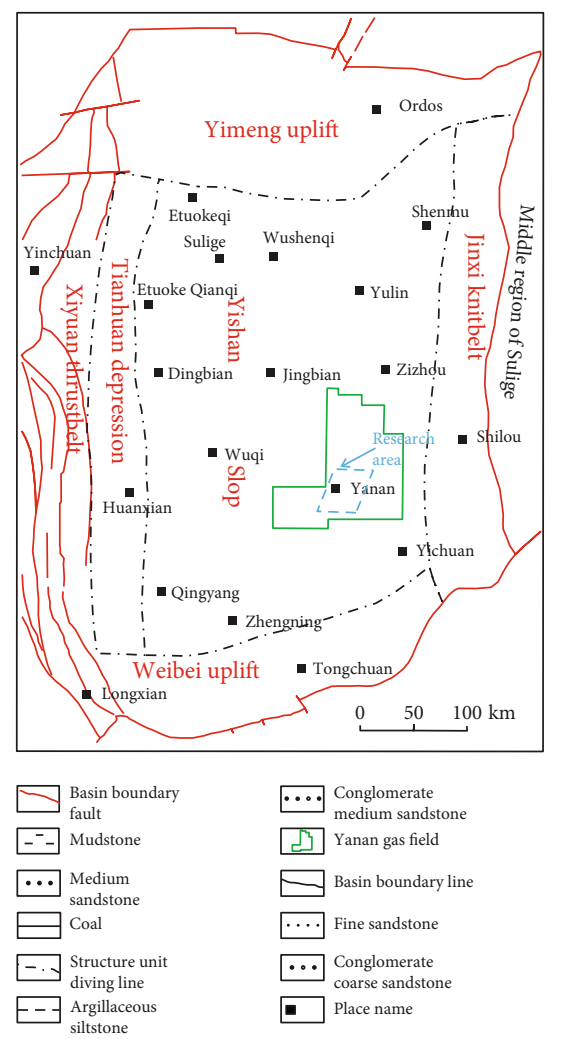

(a)

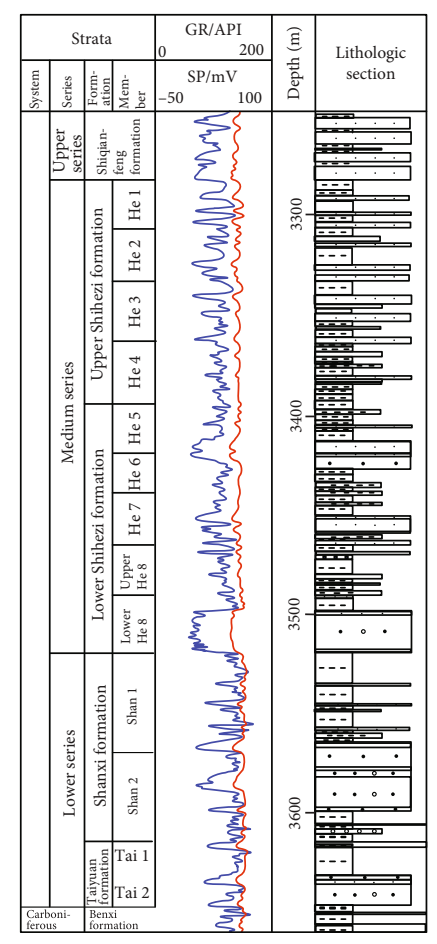

(b)

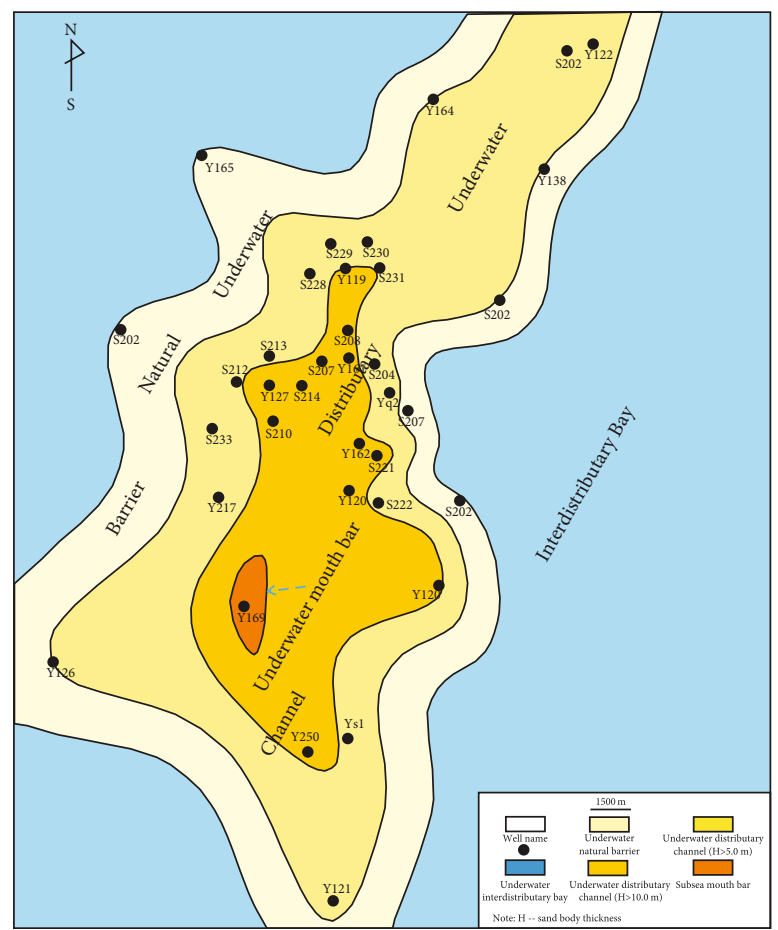

(c)

FIGURE 1: (a) Location of the research area. (b) Well logs of the Shanxi Formation. (c) Sedimentary characteristics of the research area (modified from [26, 27]).

mainly distribute in sandstone. The edges are rough and like a bay, long strip, and hemisphere. Solution pores are usually irregular, with the size between $5 \mu \mathrm{m}$ and $50 \mu \mathrm{m}$, associated with feldspar, rock debris, etc., and connected by fine dissolved joints 


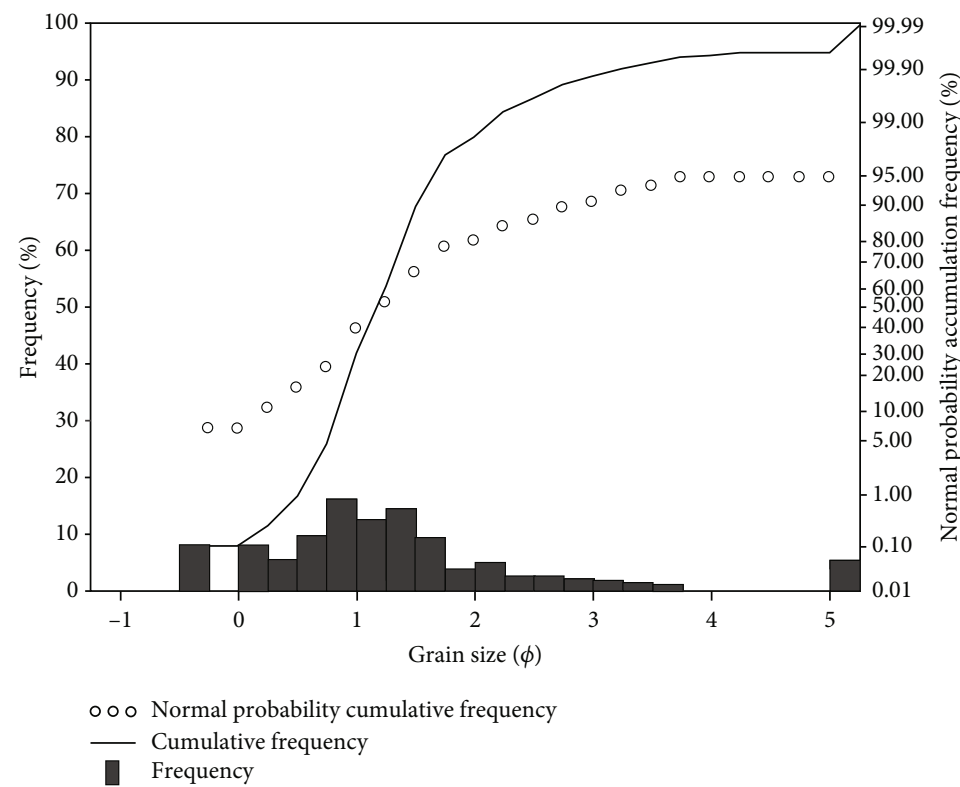

(a)

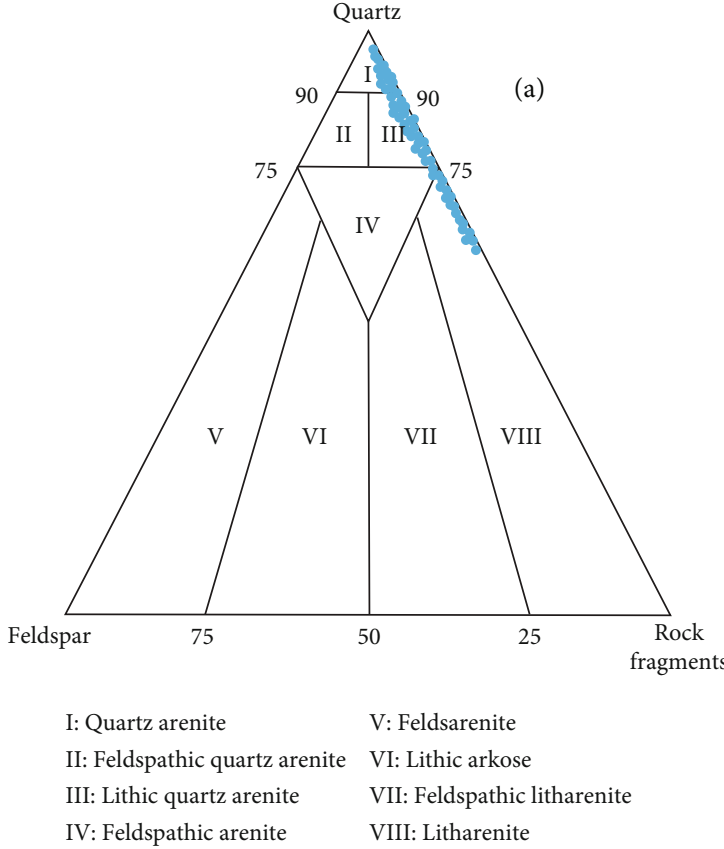

(b)

Figure 2: Grain size distribution and rock classification of Shan-2 Member in the Shanxi Formation.

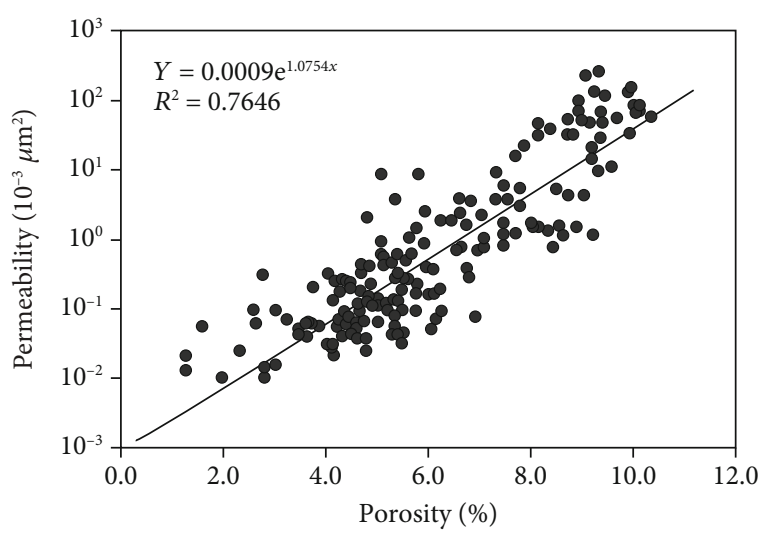

FIGURE 3: Relationship between porosity and permeability of Shan-2 Member of the Shanxi Formation in the research area.

(2) Intragranular dissolution pores: feldspar is generally subjected to dissolution under the acidic diagenetic condition. Honeycomb-like intragranular solution pores develop following the dissolution of feldspar granules and matrix in volcanic rock fragments. Phyllite, biotite, and other pseudomatrix are dissolved to form intragranular micropores

3.3.3. Intercrystalline Microspores. The interstitial material pores, which can be identified through CTS, and the kaolinite intercrystalline micropores, which have good crystallinity and pore size of higher than $3.0 \mu \mathrm{m}$, are the main types (Figure 4(c)). Such pores, which mainly distribute in the intergranular pores and secondary dissolution pores of feld- spars and debris, are commonly seen in sandstone in each layer in the research area. The pores have nonuniform sizes, which are dominated by crystal sizes and packing degree, and distribute nonuniformly. Kaolinite crystals formed by rock fragment alteration are so poorly crystalized that kaolinite crystal accounts for less than $10 \%$ of kaolinite and has the pore diameter of less than $2.0 \mu \mathrm{m}$.

3.3.4. Microfractures. The observations of CTS and SEM show that the microfracture pores in the research area are not developed very well and thereby classified into intergranular joints and rock fractures. Rock fractures are so narrow as to penetrate plastic debris and matrix (Figure 4(d)). Although rock fractures distribute much less common than intergranular joints, they provide the pathways for largescale fluid migration, creating the potential conditions for generation of dissolved secondary pores [11, 32-34].

3.4. Pore Structure Characteristics. According to the analysis of thin slices and mercury intrusion experiment, the pores in the Shan-2 Member include $38.16 \%$ fine pores $(1.0 \mu \mathrm{m}<r<10 \mu \mathrm{m}), 25.75 \%$ small pores $(10 \mu \mathrm{m}<r<50)$, $22.81 \%$ medium pores $(50 \mu \mathrm{m}<r<100)$, and $8.61 \%$ micro pores $(r<1.0 \mu \mathrm{m})$. Throat types are mainly microthroat $(0.1 \mu \mathrm{m}<r<1.0 \mu \mathrm{m})$, accounting for $65.22 \%$ of the total throat, followed by sorption throat $(r<0.1 \mu \mathrm{m})$, accounting for $25.47 \%$ of the statistics; fine throat $(1.0 \mu \mathrm{m}<r<2.0 \mu \mathrm{m})$ only takes up $7.78 \%$ of the total throat; other throats of which radius is higher than $2.0 \mu \mathrm{m}$ are throat or fractures formed by strong dissolution, and this throat takes only a small percentage of the total throat amount $(<5.0 \%)$. Plateau of the mercury intrusion curve is not obvious, and a steep slope is 


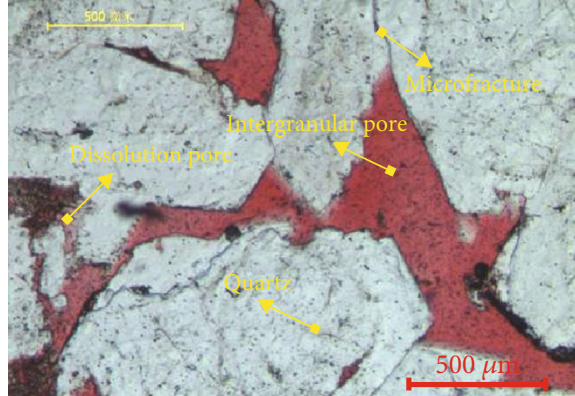

(a)

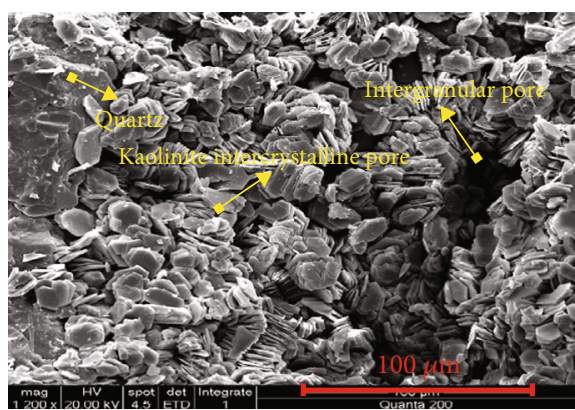

(c)

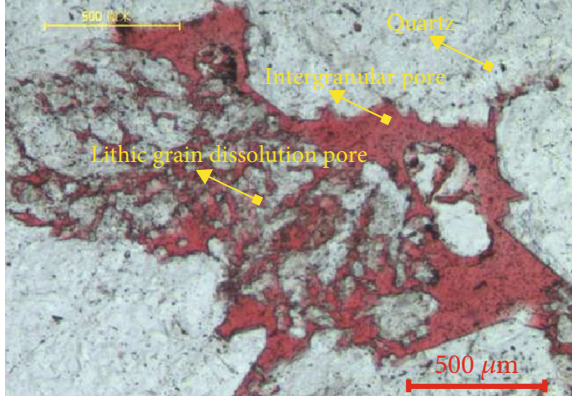

(b)

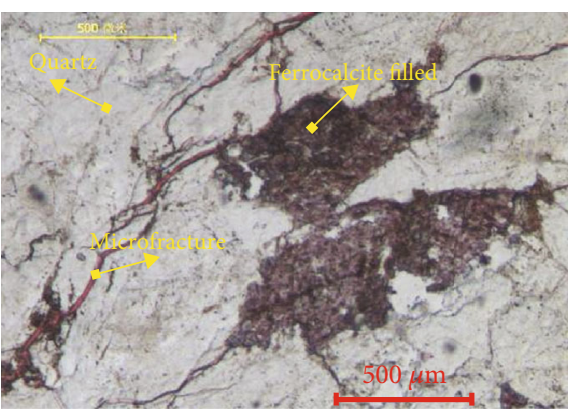

(d)

FiguRE 4: Micropore structure of the samples in the research area. (a) Well Y169, $2763.47 \mathrm{~m}$, CTS. (b) Well Y120, $2677.41 \mathrm{~m}$, CTS. (c) Well Y123, 2587.62 m, SEM. (d) Well Y162, 2727.26 m, CTS.

TABle 1: Mercury-injection data of the Shan-2 Member of the Shanxi Formation in the research area.

\begin{tabular}{lcccccccc}
\hline Type & $\Phi, \%$ & $K, 10^{-3} \mu \mathrm{m}^{2}$ & $P_{d}, \mathrm{MPa}$ & $P_{50}, \mathrm{MPa}$ & $r_{50}, \mu \mathrm{m}$ & $S_{\text {Hgmax }} \%$ & $P_{\mathrm{C}}$ & $\mathrm{SN}$ \\
\hline I & $>6.0$ & $>1.0$ & $<0.5$ & $<1.5$ & $>0.5$ & $>80.0$ & IP, DP-IP & 7 \\
II & $5.0 \sim 9.0$ & $0.1 \sim 2.0$ & $0.5 \sim 1.5$ & $2.0 \sim 10$ & $0.1 \sim 0.5$ & $70-90$ & DP-IP, IP-DP & 24 \\
III & $4.0 \sim 7.5$ & $0.1 \sim 0.5$ & $1.0 \sim 10.0$ & $15 \sim 30$ & $0.05 \sim 0.1$ & $50 \sim 80$ & DP, MP-DP & 30 \\
IV & $<6.0$ & $/$ & $/$ & $/$ & $/$ & $<50.0$ & MF, DP-MF & 9 \\
\hline
\end{tabular}

$\Phi$ : porosity; K: permeability; $\mathrm{P}_{\mathrm{d}}$ : displacement pressure; $\mathrm{P}_{50}$ : medium pressure; $\mathrm{r}_{50}$ : medium radius; $\mathrm{S}_{\mathrm{Hgmax}}$ : maximum mercury saturation; $\mathrm{P}_{\mathrm{C}}$ : pore combination; SN: sample number; IP: intergranular pore; DP: dissolution pore; MP: micropore; MF: microcrack.

shown, indicating poor pore throat sorting and strong pore structure microscopic heterogeneity. According to capillary pressure curves of the reservoir, pore throats can be divided into the following four types: type I (medium-small pore and fine-microthroat); type II (small-fine pore and microthroat); type III (fine pore and micro sorption throat); and type IV (fine-micropore and fine-microthroat) (Table 1, Figure 5).

3.5. Analysis of Influencing Factors of Reservoir Characteristics. The pores in the Shan- 2 Member have a complicated structure and strong microscopic heterogeneity. This gas reservoir has low porosity and ultra-low permeability, and its characteristics are mainly controlled by sedimentation and diagenesis.

3.5.1. Sedimentation. Sedimentation plays an important role in reservoir development and properties [35]. Sedimentary microfacies, such as subaqueous distributary channel, chan- nel mouth bar, subaqueous levee, and subaqueous interdistributary bay develop in the Shan-2 Member, which is formed by delta front subfacies sedimentation. As the favorable zone in the research area, the subaqueous distributary channel has strong hydrodynamic force and good sorting performance, contains relatively small amount of clay and matrix, and shows high compositional maturity and relatively high porosity and permeability, so it becomes a good accumulation space. For other sedimentary facies, however, its porosity and permeability decrease drastically under compaction and cementation due to weak hydrodynamic force and the high content of interstitial substances, such as fine particles and matrix (Figures 6 and 7).

It is found that the size of terrigenous debris that makes up the sandstone determines the intergranular pore size. Generally, larger pores often exist in coarse sandstone, while smaller pore often exists in smaller sandstone. Therefore, the sandstone with bigger grain size has the higher porosity and permeability (Figure 7). Thus, it is concluded that high- 

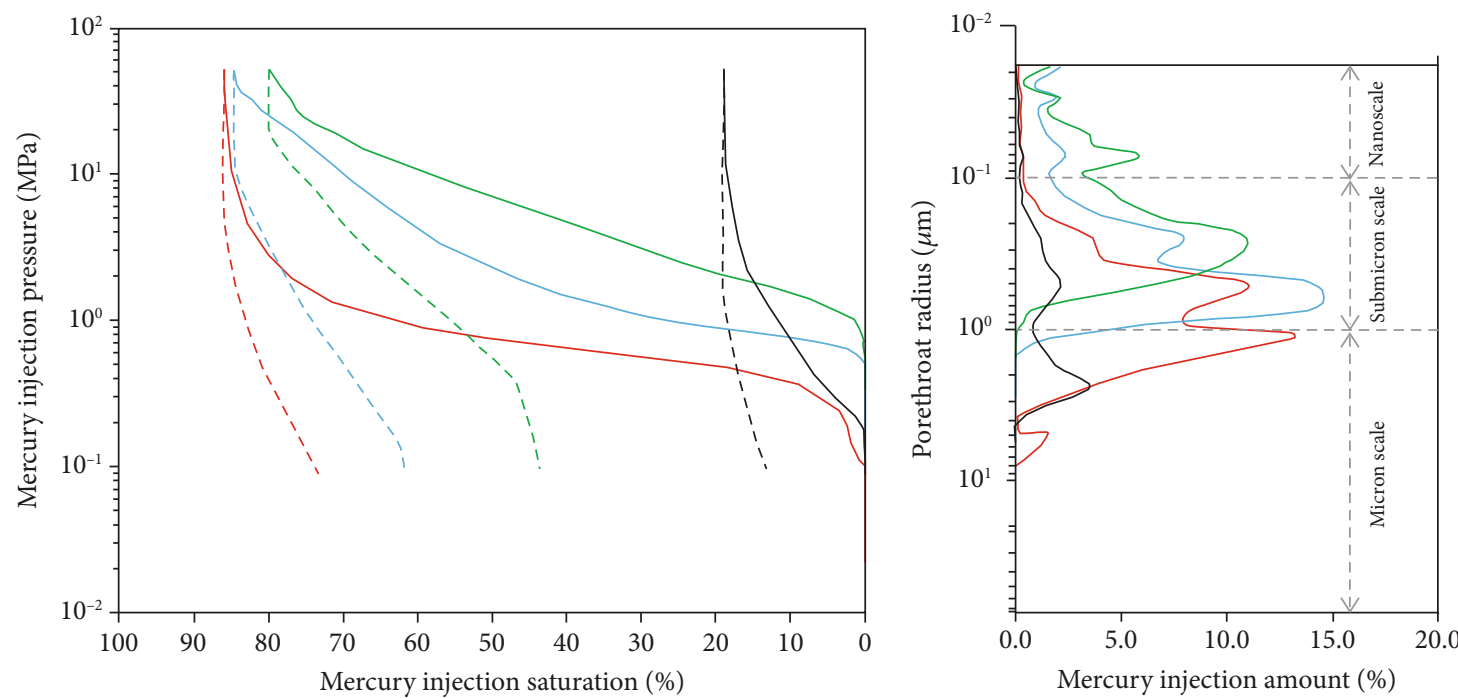

- Type I: medium-small pore and fine microthroat Well Y169, $2763.47 \mathrm{~m}, \phi: 9.86 \%, K: 1.522 \times 10^{-3} \mu \mathrm{m}^{2}$

_ Type II: small-fine pore and microthroat Well Y120, $2677.41 \mathrm{~m}, \phi: 7.29 \%, K: 0.625 \times 10^{-3} \mu \mathrm{m}^{2}$

- Type III: fine pore and microsorption throat Well Y123, $2597.62 \mathrm{~m}, \phi: 5.29 \%, K: 0.146 \times 10^{-3} \mu \mathrm{m}^{2}$

- Type IV: fine micropore and fine-microthroat Well Y162, $2727.26 \mathrm{~m}, \phi: 4.21 \%, K: 1.681 \times 10^{-3} \mu \mathrm{m}^{2}$

FiguRE 5: Characteristics of mercury intrusion curves and pore structure of samples in the research area.

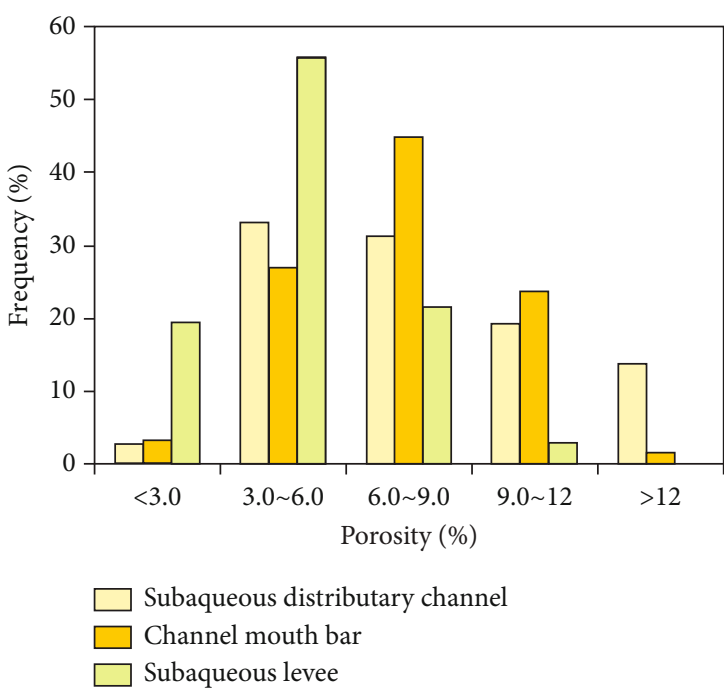

(a)

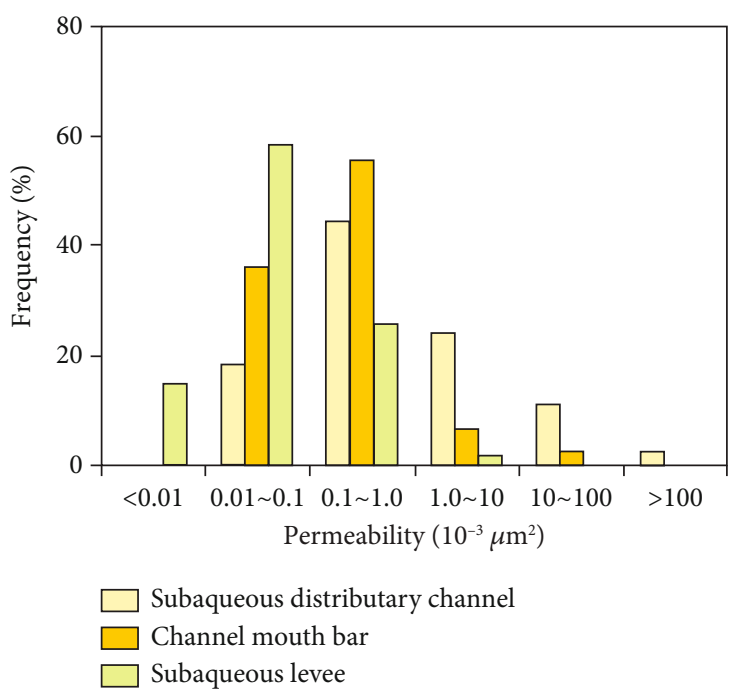

(b)

FIGURE 6: Distribution of porosity and permeability of different sedimentary microfacies.

quality reservoirs often develop in sandstone with good roundness and sorting performance and big grain size. This is because primary pores develop in the rocks with coarse grains (coarse and fine sandstone), good sorting performance, and low matrix content. The acidic fluid easily permeates into the rock and the dissolution pervades the reservoir, resulting in good physical properties [34, 36, 37]. Comprehensive research shows that the grains with good physical properties are generally fine or above in the reservoirs.

\subsubsection{Diagenesis}

(1) Effects of Compaction and Pressure Solution on Reservoir Porosity. The deeply buried quartz in the Shan-2 Member undergoes brittle fracture due to formation stress (Figure 8(a)). Flexible detrital particles (such as mica and argillaceous debris) are bent and orientated or semiorientated due to compaction and pseudomatrixization. It is commonly seen that grains show long contact due to quartz secondary overgrowth. Concave-convex or suture contact is also observed. 


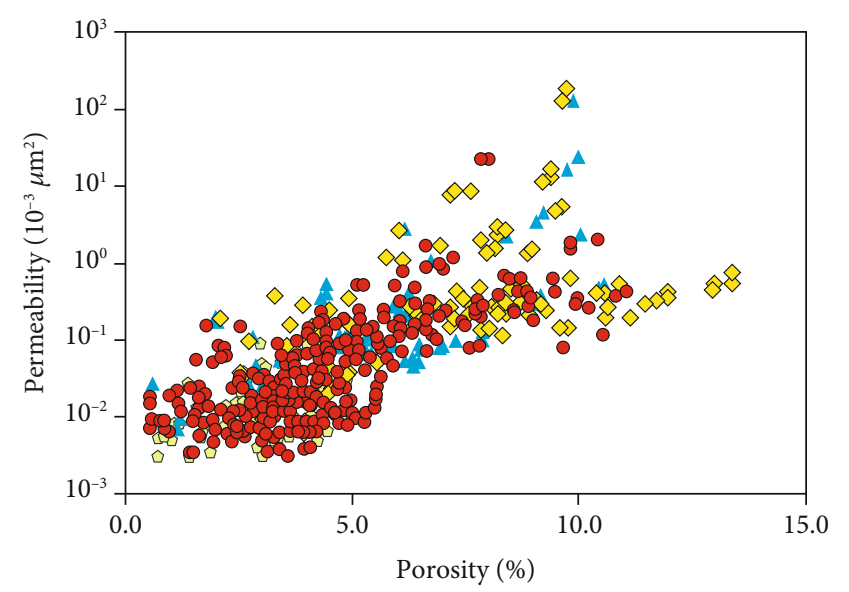

$\Delta$ Conglomeratic sandstones $\diamond$ Coarse sandstones

- Fine sandstones $\quad$ Siltstones

FIGURE 7: Relationship between porosity and permeability of different sandstone types.

These phenomena indicate that the sandstone in this area has undergone strong compaction and pressure solution. The compaction rate could quantitatively indicate the compaction degree (Table 2) $[38,39]$. Primary porosity is set between 33.5 and $39.7 \%, 35.8 \%$ on average, and the calculated compaction rate of sandstone in the Shan-2 Member is $36.5 \sim 76.2 \%, 53.45 \%$ on average. The loss of primary porosity is $20.52 \%$ due to compaction.

(2) Effects of Cementation on Reservoir. Clay mineral cementation, siliceous cementation, and carbonate cementation are commonly seen in the research area. Illite and I/M mixed layers widely develop in the sandstone with the high rock fragment content and distribute in the intergranular pores in the forms of fine scaly, colloid, or loccular aggregates. Under SEM, the I/M mixed layer unit is like bent flake, and the aggregate is honeycomb-shaped and has a spike-like protrusion. Illite is irregular, fibrous, acicular, and hair-like (Figure 8(b)). The I/M mixed layer in the research area is the intermediate product of the transformation of montmorillonite to illite and is dominated by the illite-rich layer in its late evolution stage. Clay minerals of the I/M mixed layer barely results in the loss of primary intergranular pores, but greatly influences the permeability due to the fact that the bridged coil-like and silk-like crystals clog the throats $[41,42]$. Chlorite, which is rarely seen in Shan-2 sandstone, shows thin film or pore-filling form (Figure 8(c)).

Kaolinite, which widely develops in the reservoir, can be divided into two types according to particle morphology, crystallinity, etc. $[43,44]$ : one forms in the early stage of diagenesis, has imperfect crystal shape, distributes on the wormlike or scattered flaky particle surfaces, develops by the dissolution of feldspar in acidic water, and mainly fills the pores; intergranular pores do not develop, and irregular dissolved edges develop locally (Figure 8(d)). The other one forms in the late stage of diagenesis and has relatively good crystal shape, and its single crystal is pseudohexagonal. It is precipitated directly from pore solution or evolved from the earlier kaolinite with small crystal. The aggregation is loosely packed in book-like form in intergranular pores or feldspar secondary pores. Intergranular pores are well develop (Figure $8(\mathrm{~d})$ ). On one hand, the intergranular authigenic kaolinite forms a large amount of intercrystalline micropores. On the other hand, it also increases the pressure resistance of sandstone [45].

Authigenic siliceous cements, which are common in the research area, are mainly in the form of quartz overgrowth. The observation under the CTS and the cathodoluminescent slice shows most of quartz crystals that exhibit secondary overgrowth, which belongs to grades II to III. The quartz secondary overgrowth edges are separated from the detrital quartz by a very thin clay film. Its authigenic crystal surfaces develop well. The enlarged quartz is mutually fitted or tightly mosaic in concave-convex contact and mostly grows in the pore-filling form in the pore walls or in solution pores of feldspar (Figures 8(a), 8(d), and 8(e)). Although the secondary quartz overgrowth partially inhibits the compaction, the pores are blocked due to authigenic rock overgrowth along the pore space with diagenesis (Figures $8(\mathrm{a}), 8(\mathrm{~d})$, and $8(\mathrm{e})$ ). Thus, the porosity and permeability of the reservoir decrease [46].

Carbonate cements are very common in sandstone in the Shan-2 Member and mainly occur as intergranular cements, metasomatic materials, or fillings in the secondary pores. They always show a fine-medium crystalline structure or sometimes muddy structure and mainly contain alcite, iron calcite (the main components), iron dolomite, and siderite. (Iron) calcite cements in the research area can be divided into two phases, early phase and late phase. The late phase is abundant. Early calcite cements are mainly microcrystalline calcite itself or the mixture with clay minerals filled in the particles (Figure 8(f)); late calcite cements are mainly iron calcite with coarse grains in the anhedral shape. It distributes irregularly among the debris particles mainly in long or concave-convex contact. Partial precipitation of calcite formed in late phase takes place after dissolution (Figures $8(\mathrm{f})$ and $8(\mathrm{~g})$ ). Transformation from early precipitation to dissolution and to late precipitation reflects that the pore water properties change from alkaline to acidic and then back to alkaline [46].

Carbonate minerals are major cements that reduce the sandstone properties and play a dual effect on the reservoirs. One effect is that carbonates formed in the early stage of diagenesis strengthen the sandstone's pressure resistance and protect some of the residual intergranular pores [47]. The other effect is that authigenic carbonates mainly form in the form of precipitate in the intergranular pore walls and intragranular solution pores and thereby reduce the porosity and the accumulation properties of the reservoir (Figure 9). It is calculated by cementation rate formula (Table 2) $[38,39$, 48]. He analysis of precipitate content of various cements shows that the cementation rate of sandstone in the Shan-2 Member is $9.0 \sim 63.5 \%, 44.42 \%$ on average, and the porosity loss is $16.91 \%$. 


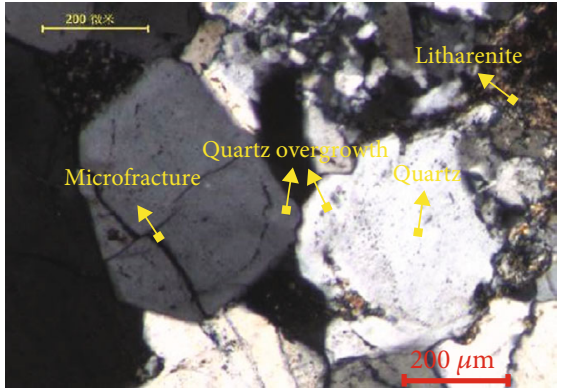

(a)

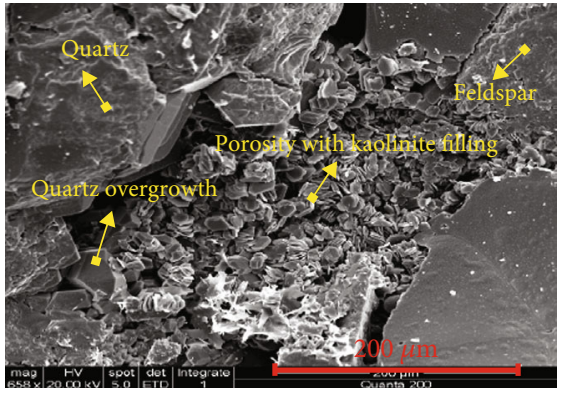

(d)

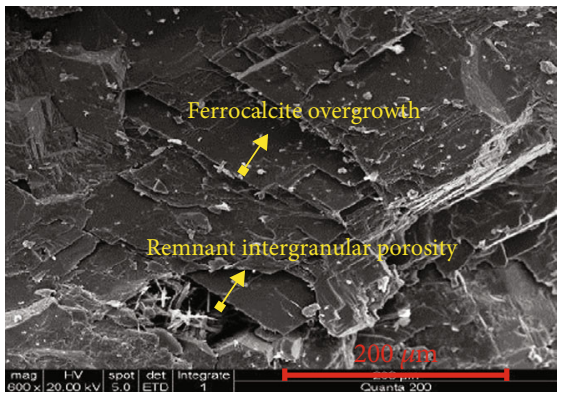

(g)

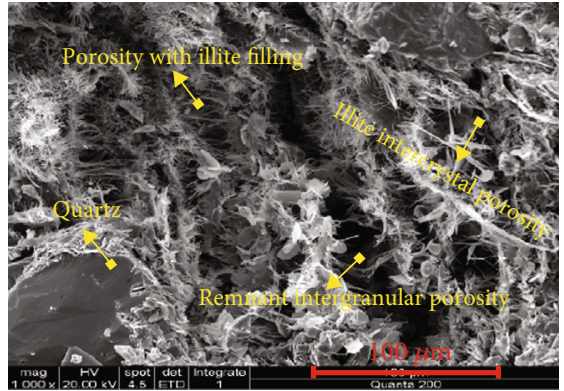

(b)

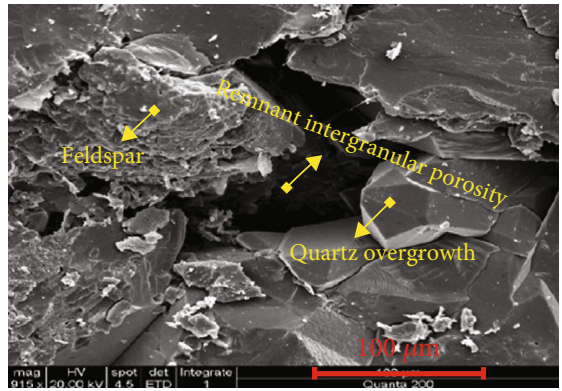

(e)

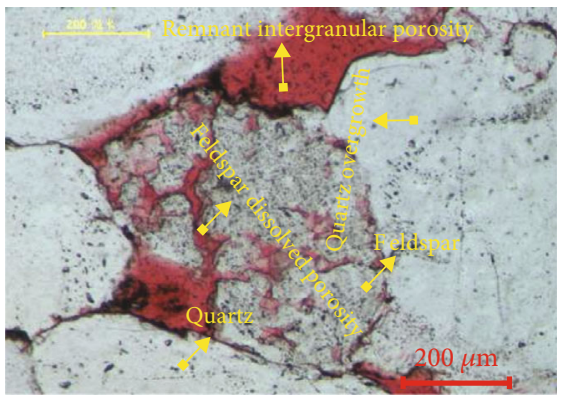

(h)

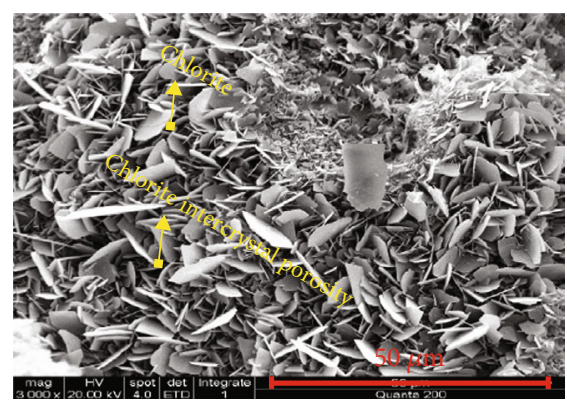

(c)

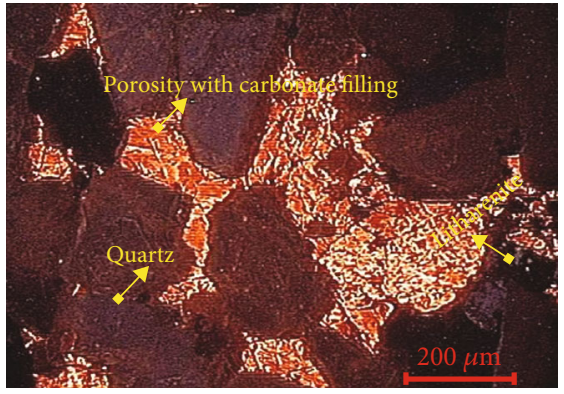

(f)

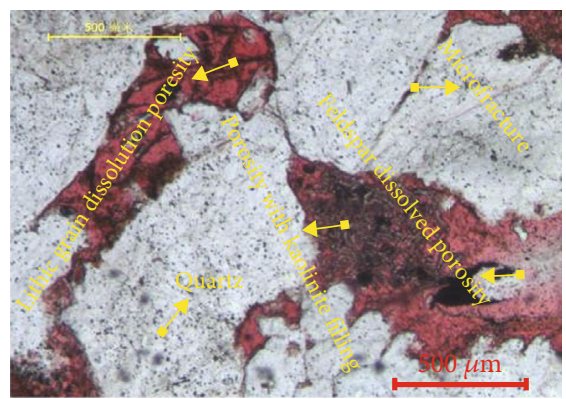

(i)

Figure 8: Microscope features of diagenesis of samples in the research area. (a) WellY169, 2629.70 m, CTS. (b) Well Y168, $2513.97 \mathrm{~m}$, SEM. (c) Well Y120, 2560.29 m, SEM. (d) Well Y126, 2718.98 m, SEM. (e) Well Y120, 2708.69 m, SEM. (f) Well Y165, 2501.65 m, CL. (g) Well Y126, 2718.98 m, SEM. (h) Well Y165, 2614.57 m, CTS. (i) Well Y218, 2612.53 m, CTS.

TABLE 2: Quantitative calculation method of porosity evolution in sandstone reservoir (modified from $[39,40]$ ).

\begin{tabular}{lc}
\hline Parameters of porosity evolution & Formula \\
\hline Primary porosity, \% & $\Phi_{1}=20.91+22.90 / S_{\mathrm{d}}$ \\
Residual porosity after compaction, $\%$ & $\Phi_{2}=\Phi_{1} \mathrm{EXP}^{\mathrm{nh}}$ \\
Porosity reduction due to cementation, $\%$ & $\Phi_{3}=C$ \\
Porosity increase due to dissolution, $\%$ & $\Phi_{4}=P_{1} \times P_{2} / P_{3}$ \\
\hline
\end{tabular}

Note: this research is not involved in microscopic fractures and pores of interstitial material due to the difficulty in their statistical approach.

(3) Effects of Dissolution and Metasomatism on Physical Properties of Reservoir. The most common metasomatism occurring in sandstone in the Shan-2 Member includes calcite replacing detrital particles, calcite replacing cements, calcite replacing argillaceous matrix, calcite argillaceous heterogeneity, and hydromica replacing quartz secondary overgrowth and intergranular microcrystalline quartz, etc. In addition, the transformation of montmorillonite to illite and chlorite, kaolinization to feldspar, and transformation between kaolinite and illite is common in this area. From the pore distribution in this area, most of the solution pores formed by metasomatism are destroyed by cementation.

Dissolution in the research area is very strong. The examination of SEM shows that a limited amount of secondary pores form by the dissolution of clay minerals, carbonate minerals, and quartz grains mainly in the surface and inside of rock fragments (Figure $8(\mathrm{~h})$ ), followed by the dissolution of feldspar (Figure 8(i)). Grains could dissolute in two cases: one is that the unstable particles such as feldspar and rock fragments are dissolved to form the dissolved intergranular pores directly; the other is that the feldspar and rock fragments are replaced by carbonate minerals and then dissolved in the metasomatic materials leading to the dissolved intragranular pores and dissolved intergranular pores formed by 


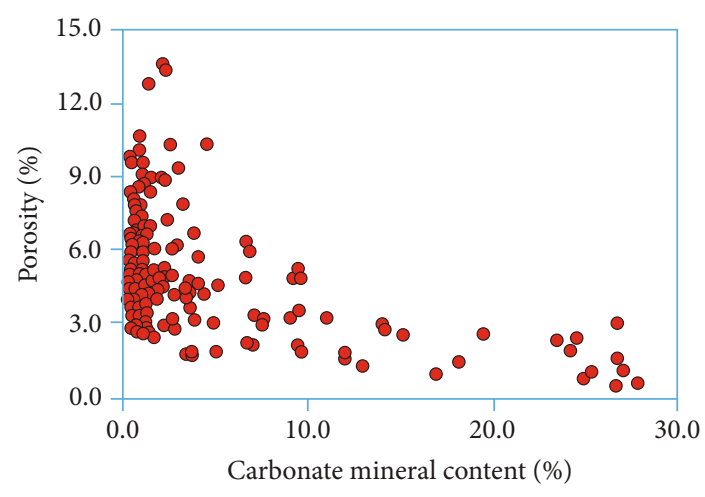

(a)

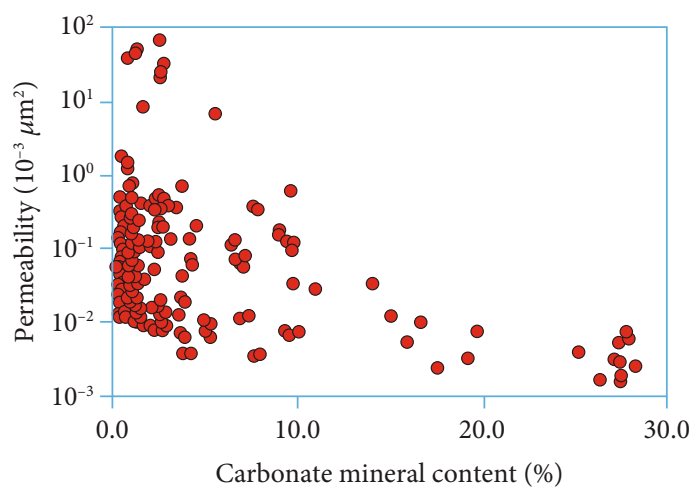

(b)

FIGURE 9: Relationship between content of carbonate minerals and petrophysical properties of samples in the research area.

dissolution of the grains [49]. Dissolution plays a constructive role in improvement of the accumulation properties of the sandstone reservoir. Although some of the solution pores are filled by iron carbonate cements in the late stage, some secondary pores remained. The amount of new pores formed by dissolution is calculated from the cementation rate formula (Table 2). The calculation result is about $2.68 \%$.

\section{Conclusion}

(1) Lithology of the Shan-2 Member is mainly mediumcoarse lithic quartzarenite and quartzarenite with high compositional maturity and low structural maturity. Solution pores are the main accumulation spaces, followed by primary pores. Intragranular solution pores are mainly feldspar and rock fragment solution pores. The pore types are dominated by microfine pores

(2) Shan-2 Member has four types of pores: mediumsmall pore with fine-microthroat, small-fine pore with microthroat, fine pore with microsorption throat, and fine-micropore with fine-microthroat. The main pore type is small-medium pores, and the main throat type is microthroat. The reservoir has poor physical properties, an average porosity of $7.22 \%$ and average value of $15.69 \times 10-3 \mu \mathrm{m}^{2}$, and thereby belongs to a low porosity and low permeability gas reservoir

(3) Sedimentation is the fundamental factor affecting the reservoir characteristics. Rock types, rock grain sizes, sorting performance, and matrix components are very different at different sedimentary facies. The rocks with good physical properties are fine and above sandstone, and the most favorable sedimentary facies is the underwater distributary channel in the research area

(4) Diagenesis is also an important factor affecting the accumulation properties of the Shan-2 Member. Compaction and cementation are the main factors of reducing the physical properties. The average loss of porosity due to compaction in the Shan-2 Member is $20.52 \%$, and the loss of porosity is $16.91 \%$ due to cementation. Corrosion results in a certain increase of porosity, $2.68 \%$ on average

\section{Data Availability}

The thin section and SEM images are provided by Shaanxi Key Laboratory of Advanced Stimulation Technology for Oil \& Gas Reservoirs, Xi'an Shiyou University. The physical properties and PCMI data used for this study are from the State Engineering Laboratory for Exploration and Development of Low permeability Oil and Gas Fields in China.

\section{Conflicts of Interest}

The authors declare that there are no conflicts of interest regarding the publication of this paper.

\section{Acknowledgments}

This research was supported by the Open Fund of Key Laboratory of Coal Resources Exploration and Comprehensive Utilization, Ministry of Land and Resources (grant numbers KF2019-1 and KF2020-2), China Postdoctoral Science Foundation (grant number 2018M643554), National Natural Science Foundation of China (grant numbers 41702146 and 51934005), Young science and Technology Talents Foundation of Shaanxi Province (grant number 2019KJXX-054), and Open Fund of Shaanxi Key Laboratory of Advanced Stimulation Technology for Oil \& Gas Reservoirs, grant number 20JS120.

\section{References}

[1] J. Lai, G. Wang, Z. Wang et al., "A review on pore structure characterization in tight sandstones," Earth-Science Reviews, vol. 177, pp. 436-457, 2018.

[2] B. Ghanbarian, C. Torres-Verdín, L. W. Lake, and M. Marder, "Gas permeability in unconventional tight sandstones: scaling up from pore to core," Journal of Petroleum Science and Engineering, vol. 173, pp. 1163-1172, 2019. 
[3] D. Liu, Z. Gu, R. Liang et al., "Impacts of pore-throat system on fractal characterization of tight sandstones," Geofluids, vol. 2020, Article ID 4941501, 17 pages, 2020.

[4] H. Huang, T. Babadagli, X. Chen, H. Li, and Y. Zhang, "Performance comparison of novel chemical agents for mitigating water-blocking problem in tight gas sandstones," SPE Reservoir Evaluation \& Engineering, vol. 23, pp. 1150-1158, 2020.

[5] S. Chen, D. Yin, N. Jiang, F. Wang, and Z. Zhao, "Mechanical properties of oil shale-coal composite samples," International Journal of Rock Mechanics and Mining Sciences, vol. 123, p. 104120, 2019.

[6] G. Sheng, Y. Su, and W. Wang, "A new fractal approach for describing induced-fracture porosity/permeability/compressibility in stimulated unconventional reservoirs," Journal of Petroleum Science and Engineering, vol. 179, pp. 855-866, 2019.

[7] J. Lai, X. Fan, B. Liu et al., "Qualitative and quantitative prediction of diagenetic facies via well logs," Marine and Petroleum Geology, vol. 120, 2020.

[8] D. Ren, D. Zhou, D. Liu, F. Dong, S. Ma, and H. Huang, "Formation mechanism of the upper Triassic Yanchang formation tight sandstone reservoir in Ordos Basin-take Chang 6 reservoir in Jiyuan oil field as an example," Journal of Petroleum Science and Engineering, vol. 178, pp. 497-505, 2019.

[9] D. Liu, W. Sun, D. Ren, and C. Li, "Quartz cement origins and impact on storage performance in Permian Upper Shihezi Formation tight sandstone reservoirs in the northern Ordos Basin, China," Journal of Petroleum Science and Engineering, vol. 178, pp. 485-496, 2019.

[10] S. Hu, Y. Tan, H. Zhou et al., "Anisotropic modeling of layered rocks incorporating planes of weakness and volumetric stress," Energy Science \& Engineering, vol. 8, no. 3, pp. 789-803, 2020.

[11] D. Liu, W. Sun, D. Li, J. Shi, and D. Ren, "Pore structures characteristics and porosity evolution of tight sandstone reservoir: taking the Chang 63 tight sandstones reservoir of Huaqing area in Ordos Basin as an instance," FEB-Fresenius Environmental Bulletin, vol. 27, pp. 1043-1052, 2018.

[12] D. Liu, W. Sun, and D. Ren, "Experimental investigation of pore structure and movable fluid traits in tight sandstone," PRO, vol. 7, no. 3, p. 149, 2019.

[13] N. Zhang, W. Liu, Y. Zhang, P. Shan, and X. Shi, "Microscopic pore structure of surrounding rock for underground strategic petroleum reserve (SPR) caverns in bedded rock salt," Energies, vol. 13, no. 7, p. 1565, 2020.

[14] G. Sheng, H. Zhao, Y. Su et al., "An analytical model to couple gas storage and transport capacity in organic matter with noncircular pores," Fuel, vol. 268, p. 117288, 2020.

[15] J. Qiao, J. Zeng, S. Jiang, and Y. Wang, "Impacts of sedimentology and diagenesis on pore structure and reservoir quality in tight oil sandstone reservoirs: implications for macroscopic and microscopic heterogeneities," Marine and Petroleum Geology, vol. 111, pp. 279-300, 2020.

[16] W. Dou, L. Liu, K. Wu, Z. Xu, X. Liu, and X. Feng, "Diagenetic heterogeneity, pore throats characteristic and their effects on reservoir quality of the upper Triassic tight sandstones of Yanchang Formation in Ordos Basin, China," Marine and Petroleum Geology, vol. 98, pp. 243-257, 2018.

[17] D. Xiao, S. Jiang, D. Thul, S. Lu, L. Zhang, and B. Li, "Impacts of clay on pore structure, storage and percolation of tight sandstones from the Songliao Basin, China: implications for genetic classification of tight sandstone reservoirs," Fuel, vol. 211, pp. 390-404, 2018.
[18] X. Wang, J. Hou, S. Song et al., "Combining pressurecontrolled porosimetry and rate-controlled porosimetry to investigate the fractal characteristics of full-range pores in tight oil reservoirs," Journal of Petroleum Science and Engineering, vol. 171, pp. 353-361, 2018.

[19] C. Wang, B. Shen, J. Chen et al., "Compression characteristics of filling gangue and simulation of mining with gangue backfilling: an experimental investigation," Geomechanics and Engineering, vol. 20, no. 6, pp. 485-495, 2020.

[20] A. Reinicke, E. Rybacki, S. Stanchits, E. Huenges, and G. Dresen, "Hydraulic fracturing stimulation techniques and formation damage mechanisms-implications from laboratory testing of tight sandstone-proppant systems," Geochemistry, vol. 70, pp. 107-117, 2010.

[21] Y. Zhang, S. Cao, N. Zhang, and C. Zhao, “The application of short-wall block backfill mining to preserve surface water resources in Northwest China," Journal of Cleaner Production, vol. 261, 2020.

[22] P. Shan and X. Lai, “An associated evaluation methodology of initial stress level of coal-rock masses in steeply inclined coal seams, Urumchi coal field, China," Engineering Computations, vol. 37, no. 6, pp. 2177-2192, 2020.

[23] Y. Yang, W. Li, and L. Ma, "Tectonic and stratigraphic controls of hydrocarbon systems in the Ordos basin: a multicycle cratonic basin in Central China," AAPG Bulletin, vol. 89, no. 2, pp. 255-269, 2005.

[24] S. Dai, D. Ren, C.-L. Chou, S. Li, and Y. Jiang, "Mineralogy and geochemistry of the no. 6 coal (Pennsylvanian) in the Junger Coalfield, Ordos Basin, China," International Journal of Coal Geology, vol. 66, no. 4, pp. 253-270, 2006.

[25] W.-Z. Zhang, H. Yang, J.-F. Li, and J. Ma, "Leading effect of high-class source rock of Chang 7 in Ordos Basin on enrichment of low permeability oil-gas accumulation-Hydrocarbon generation and expulsion mechanism," Shiyou Kantan Yu Kaifa(Petroleum Exploration and Development), vol. 33, no. 3, pp. 289-293, 2006.

[26] J. Dai, J. Li, X. Luo et al., "Stable carbon isotope compositions and source rock geochemistry of the giant gas accumulations in the Ordos Basin, China," Organic Geochemistry, vol. 36, no. 12, pp. 1617-1635, 2005.

[27] L. Zhang, G. Bai, X. Luo et al., "Diagenetic history of tight sandstones and gas entrapment in the Yulin gas field in the central area of the Ordos Basin, China," Marine and Petroleum Geology, vol. 26, no. 6, pp. 974-989, 2009.

[28] E. W. Washburn, "The dynamics of capillary flow," Physical Review, vol. 17, no. 3, pp. 273-283, 1921.

[29] W. R. Purcell, "Capillary pressures-their measurement using mercury and the calculation of permeability therefrom," Journal of Petroleum Technology, vol. 1, no. 2, pp. 39-48, 2013.

[30] D. J. K. Ross and R. M. Bustin, "The importance of shale composition and pore structure upon gas storage potential of shale gas reservoirs," Marine and Petroleum Geology, vol. 26, no. 6, pp. 916-927, 2009.

[31] Y. Wang, Y. Zhu, S. Chen, and W. Li, "Characteristics of the nanoscale pore structure in Northwestern Hunan shale gas reservoirs using field emission scanning electron microscopy, high-pressure mercury intrusion, and gas adsorption," Energy \& Fuels, vol. 28, no. 2, pp. 945-955, 2014.

[32] N. Jiang, C. Wang, H. Pan, D. Yin, and J. Ma, "Modeling study on the influence of the strip filling mining sequence on 
mining-induced failure," Energy Science \& Engineering, vol. 8, no. 6, pp. 2239-2255, 2020.

[33] J. Su, G. Chai, L. Wang et al., "Pore-scale direct numerical simulation of particle transport in porous media," Chemical Engineering Science, vol. 199, pp. 613-627, 2019.

[34] G. Feng, Y. Kang, X. Wang, Y. Hu, and X. Li, "Investigation on the failure characteristics and fracture classification of shale under Brazilian test conditions," Rock Mechanics and Rock Engineering, vol. 53, pp. 1-16, 2020.

[35] C. Legout, I. G. Droppo, J. Coutaz, C. Bel, and M. Jodeau, "Assessment of erosion and settling properties of fine sediments stored in cobble bed rivers: the arc and Isère alpine rivers before and after reservoir flushing," Earth Surface Processes and Landforms, vol. 43, no. 6, pp. 1295-1309, 2018.

[36] S. Zhi, D. Elsworth, J. Wang, Q. Gan, and S. Liu, "Hydraulic fracturing for improved nutrient delivery in microbiallyenhanced coalbed-methane (MECBM) production," Journal of Natural Gas Science and Engineering, vol. 60, pp. 294-311, 2018.

[37] G. Feng, X. Wang, M. Wang, and Y. Kang, "Experimental investigation of thermal cycling effect on fracture characteristics of granite in a geothermal-energy reservoir," Engineering Fracture Mechanics, vol. 235, 2020.

[38] J. L. Luo, X. S. Liu, X. Y. Fu, R. Kang, and Y. Jia, "Impact of petrologic components and their diagenetic evolution on tight sandstone reservoir quality and gas yield: a case study from he 8 gas-bearing reservoir of upper Paleozoic in northern Ordos Basin," Earth Science, vol. 39, no. 5, pp. 537-545, 2014.

[39] T. R. Taylor, M. R. Giles, L. A. Hathon et al., "Sandstone diagenesis and reservoir quality prediction: models, myths, and reality," AAPG Bulletin, vol. 94, no. 8, pp. 10931132,2010

[40] C. Zhang, W. Sun, and H. Gao, "Reservoir diagenetic facies and porosity evolution pathways of Chang 8 formation in Huachi Ordos Basin,” Earth Science, vol. 39, no. 4, pp. 411420, 2014.

[41] K. Xi, Y. Cao, J. Jahren et al., "Diagenesis and reservoir quality of the lower cretaceous Quantou Formation tight sandstones in the southern Songliao Basin, China," Sedimentary Geology, vol. 330, pp. 90-107, 2015.

[42] Y. Wang, L. Liu, S. Li et al., "The forming mechanism and process of tight oil sand reservoirs: a case study of chang 8 oil layers of the upper triassic yanchang formation in the western jiyuan area of the ordos basin, china," Journal of Petroleum Science and Engineering, vol. 158, pp. 29-46, 2017.

[43] S. Huang, Y. Wu, X. Meng, L. Liu, and W. Ji, "Recent advances on microscopic pore characteristics of low permeability sandstone reservoirs," Advances in Geo-Energy Research, vol. 2, no. 2, pp. 122-134, 2018.

[44] L. Wang, J. Su, Z. Gu, and L. Tang, "Numerical study on flow field and pollutant dispersion in an ideal street canyon within a real tree model at different wind velocities," Computers \& Mathematics with Applications, vol. 81, no. 6, pp. 679-692, 2021.

[45] J. Yan, S. Zhang, J. Wang, Q. Hu, M. Wang, and J. Chao, "Applying fractal theory to characterize the pore structure of lacustrine shale from the Zhanhua depression in Bohai Bay Basin, Eastern China," Energy \& Fuels, vol. 32, no. 7, pp. 7539-7556, 2018.
[46] J. Wang, Y. Cao, K. Liu, A. Costanzo, and M. Feely, "Diagenesis and evolution of the lower Eocene red-bed sandstone reservoirs in the Dongying Depression, China," Marine and Petroleum Geology, vol. 94, pp. 230-245, 2018.

[47] L. Wu, Y. Lu, S. Jiang, Y. Lu, X. Liu, and H. Hu, "Pore structure characterization of different lithofacies in marine shale: a case study of the upper Ordovician Wufeng-Lower Silurian Longmaxi formation in the Sichuan Basin, SW China," Journal of Natural Gas Science and Engineering, vol. 57, pp. 203-215, 2018.

[48] O. Walderhaug, "Kinetic modeling of quartz cementation and porosity loss in deeply buried sandstone reservoirs," AAPG bulletin, vol. 80, no. 5, pp. 731-745, 1996.

[49] H. Zhang, J. Peng, X. Lin, B. Li, and Q. Xia, "Diagenesis and its controlling factors of lower Donghetang formation tight sandstone reservoir in Bachu area, Tarim Basin, China," Geosciences Journal, vol. 22, no. 2, pp. 327-336, 2018. 